\title{
Simulation of large-size plain bearings processing using a virtual prototype of machine module
}

\author{
Tatyana A. Duyun ${ }^{1, *}$, Dmitry A. Bushuev ${ }^{2}$, Maksim A. Sukharev ${ }^{2}$, and Vasiliy G. Rubanov ${ }^{2}$ \\ ${ }^{1}$ BSTU n.a. V.G. Shukhov, Department of Technology of mechanical engineering, 308012, Belgorod, \\ Kostyukova Str, 46, Russia \\ ${ }^{2}$ BSTU n.a. V.G. Shukhov, Department of Engineering Cybernetics, 308012, Belgorod, Kostyukova \\ Str, 46, Russia
}

\begin{abstract}
An approach for modeling the mechanical processing of largesize plain bearings using a virtual prototype of a special machine module built in the MSC Adams software for kinematic and dynamic analysis is presented. Kinematic and dynamic characteristics of the module and the geometric model of the machined surface are shown.
\end{abstract}

\section{Introduction}

The intensive process of wear of large-sized sliding bearings surfaces, widely used in ball mills, influences the reliability and service life of an exploited slip surface made of babbits on a tin or lead basis. Traditional technology of slip surface restoration includes scraping, which is associated with low productivity, high production costs, unstable quality, depending on the qualifications of the performer. The creation of machine tools for the restoration of the bearing surfaces of large-sized bearings with a stable roughness independent of the human factor is an urgent problem for which present research is directed.

Creating virtual prototypes using specialized software packages in the design of various machines and mechanisms is increasingly used. The virtual prototype allows performing a comprehensive analysis of the projected object, simulating its operation under the influence of operational loads and disturbing factors, carrying out strength, kinematic and dynamic calculations, optimizing design solutions [1-4]. In this paper we present the approach for simulating the kinematics and dynamics of the machine module during processing of the bearing surface of a large-sized sliding bearing using a virtual prototype built in the MSC Adams software.

\section{The task statement and analytical solution}

To improve the efficiency of large-sized bearings processing, the design of a special machine tool has been developed [5]. A feature of the proposed design is the motion of the

\footnotetext{
* Corresponding author: tanduun@mail.ru
} 
tool along the radial surface of the segment of a large-sized sliding bearing (Fig. 1). The motion of the longitudinal feed is kinematically realized using a four-link crank-and-link mechanism. Rotational motion of the crank is transmitted from the electric motor through the reducer. The rocker and the rocker convert the rotational motion of the crank into the rocking motion of the rocker arm, on which is located the cutting tool - the milling cutter.

For one full turn of the crank, the cutting tool makes one working and one idling, returning to its original position. The motion of the transverse feed is carried out at the end of the complete cycle of the mechanism consisting of working and idling stroke. Stepping motors are used to retract the tool and perform transverse feeding which is activated when the cutter crosses the rays of the laser sensors. The main motion - the rotation of the milling cutter around its own axis is realized by an asynchronous electric motor.

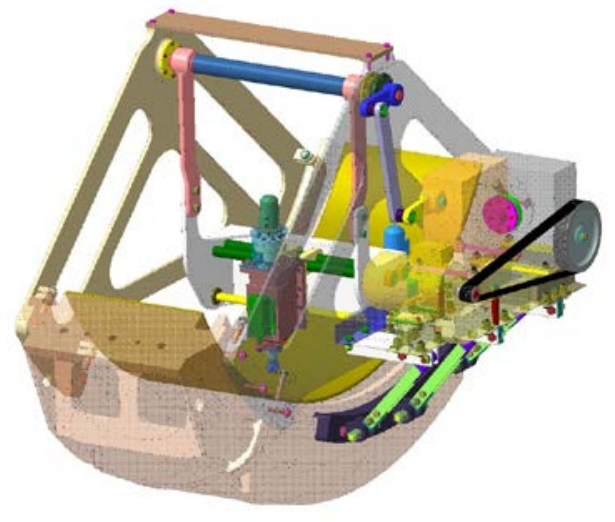

$a$

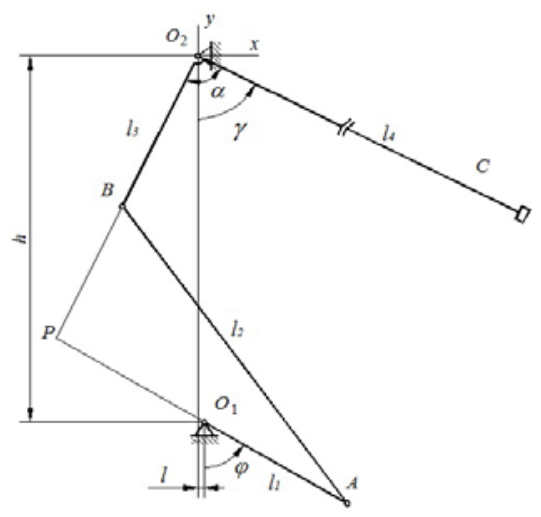

$b$

Fig. 1. The construction of the machine module: $a$ - general view; $b$ - crank-and-link mechanism

To achieve the required conditions of the milling process, the kinematic parameters of the special machine tool used in the machine module must provide the specified technological modes [6]. For this purpose, an algorithm for the machine module kinematic analyses which makes it possible to determine the output working kinematic characteristics of the actuating elements depending on the proportions of the structural elements has been developed.

Input data for the calculations are: $\omega$ - crank rotation angular velocity $O_{1} A$; $l_{1}, l_{2}, l_{3}, l_{4}$ - length of the crank $O_{1} A$, linker $A B$, arms $O_{2} B$ и $O_{2} C$, respectively; $\alpha-$ angle at the top of the rocker; $l$ и $h$ - rocker axes offset $O_{2}$ with respect to the support $O_{1}$ along horizontal and vertical, respectively.

The size of the cutting tool supply is kinematically dependent on the speed of its motion relative to the processing surface. This speed $v_{c}$ was calculated as a function of the crank angle $\varphi$ using the instantaneous velocity center in analytical form:

$$
\begin{gathered}
v_{C}=\omega \frac{B P}{A P} \frac{l_{1} \cdot l_{4}}{l_{3}}, \\
A P=\sqrt{\left(x_{A}-x_{P}\right)^{2}+\left(y_{A}-y_{P}\right)^{2}}, \\
B P=\sqrt{\left(x_{B}-x_{P}\right)^{2}+\left(y_{B}-y_{P}\right)^{2}}
\end{gathered}
$$




$$
\begin{aligned}
& \left\{\begin{array}{l}
x_{A}=l+l_{1} \sin \varphi \\
y_{A}=-h-l_{1} \cos \varphi
\end{array},\right. \\
& \left\{\begin{array}{l}
x_{B}=\frac{A x_{A}-\sqrt{A^{2} x_{A}^{2}-\left(x_{A}^{2}+y_{A}^{2}\right)\left(A^{2}-y_{A}^{2} l_{3}^{2}\right)}}{x_{A}^{2}+y_{A}^{2}}, \\
y_{B}=\frac{A-x_{A} x_{B}}{y_{A}}
\end{array}\right. \\
& \left\{\begin{array}{l}
x_{P}=\frac{\left(h x_{A}+l y_{A}\right) x_{B}}{y_{B}\left(l-x_{A}\right)+x_{B}\left(h+y_{A}\right)}, A=\frac{1}{2}\left(l_{3}^{2}-l_{2}^{2}+x_{A}^{2}+y_{A}^{2}\right) \\
y_{P}=\frac{y_{B}}{x_{B}} x_{P}
\end{array} .\right.
\end{aligned}
$$

To calculate the coordinates of the cutting tool $x_{c}, y_{c}$ were found following expressions:

$$
\left\{\begin{array}{l}
y_{C}=-\frac{|k| l_{4}}{\sqrt{1+k^{2}}}, \\
x_{C}=\frac{y_{C}}{k},
\end{array} k=\frac{x_{B} \operatorname{tg} \alpha+y_{B}}{x_{B}-y_{B} \operatorname{tg} \alpha} .\right.
$$

\section{Simulation model and results}

Analytical investigation of the presented mechanism was used to construct a simulation model and a virtual prototype in the MSC Adams software for the purpose of kinematic and dynamic analysis (Fig. 2). The flat model of the mechanism consists of four solid bodies in accordance with the design scheme [7]. The links $\mathrm{O}_{1} \mathrm{~A}, \mathrm{AB}, \mathrm{BO}_{2}, \mathrm{O}_{2} \mathrm{C}$ are specified by the standard link bodies of the MSC Adams, the masses and moments of inertia of which are determined by the detailed model created in the computer-aided design system KOMPAS3D. The $\mathrm{BO}_{2}$ link is connected to the Ground part with Revolute Joint and with the $\mathrm{O}_{2} \mathrm{C}$ link using the Fixed Joint. The other links are linked together by Revolute Joints. To the $O_{l} A$ link, using Rotational Joint Motion, a constant rotation speed $n=0.092 \mathrm{~min}^{-1}$ is applied. As external forces, resistance forces were set in the Revolute Joints, and at point $C$ a cutting force $\mathrm{F}$ applied along the normal to the $\mathrm{O}_{2} \mathrm{C}$ link.

$3 \mathrm{D}$ virtual prototype of the machine module is implemented using the Adams.Machinery module. The transmission of torque from the engine to the gearbox connected to the crank is realized using a belt drive created with the Machinery.Belt, and when creating the crossfeed chain, the Machinery.Chain is used. It allows investigating the effect of nonlinearities inherent in these transmissions on the dynamics of the entire device.
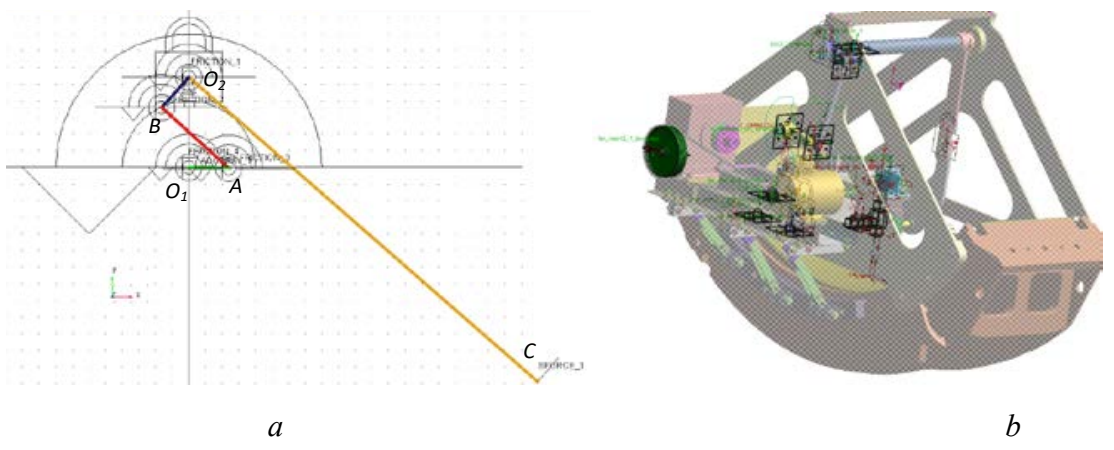

Fig. 2. The virtual prototype of the machine module: $a-2 \mathrm{D}$ model; $b-3 \mathrm{D}$ model 


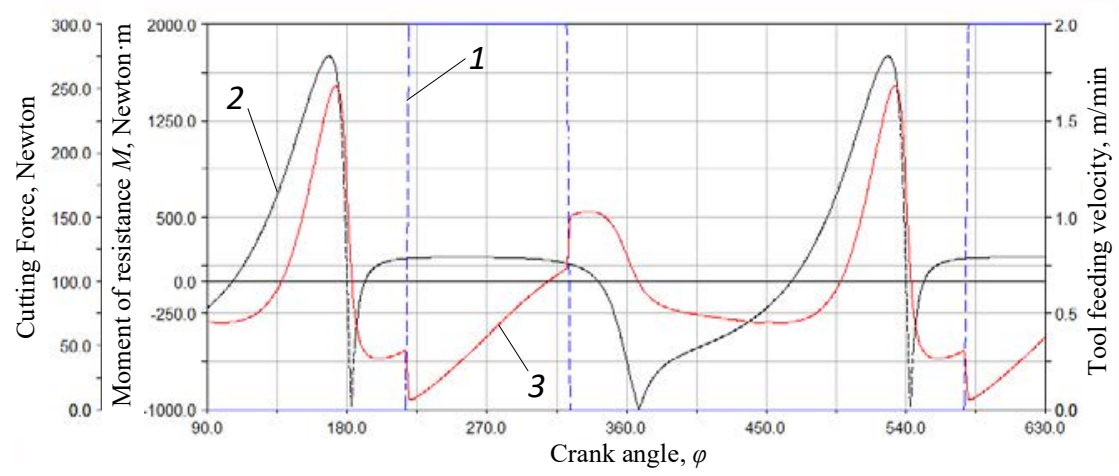

Fig. 3. Results of simulation of the actuator using a flat model: 1 - cutting force; 2 - tool feed speed; 3 - moment of resistance
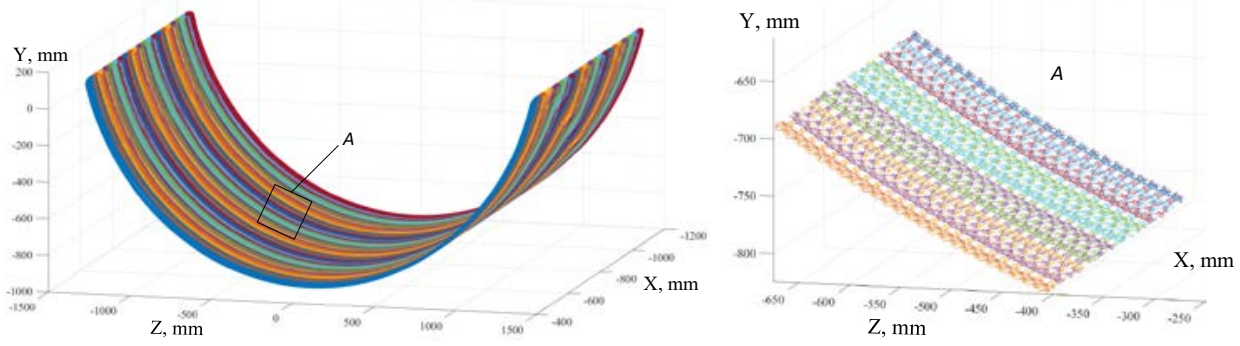

Fig. 4. Results of simulation of cutting tool motion

As a result of the dynamic analysis of the mechanism using the flat model, the force and torque characteristics were found: the moment of resistance $M$, which must be overcome in order to maintain a constant speed of rotation $n$ on the crankshaft (Fig. 3). As a result of the analysis of the 3D virtual prototype, a geometric model of the machined surface is obtained (Fig. 4). It allows predicting the quality which will obtain the machine module.

\section{Conclusions}

The developed approach using two- and three-dimensional models built in the MSC Adams software for kinematic and dynamic simulation of the machine module ensuring the mechanical processing of large-size plain bearings allows analysing the operating modes of machine tools, synthesizing and modelling the dynamics of the automatic control systems for cutting tool, transverse and longitudinal feed drives.

The article is prepared in the framework of development of the Base University on the basis of BSTU named after V.G. Shukhov.

\section{References}

1. Y. Qingni, L. Jian, P. Weiji, Y. Qingyun, Manufacturing Technology. 14 (4). pp. 600607. (2014).

2. Z. Cui, G. Wen, C. Jiang, China Mechanical Engineering. 20 (5). pp. 518-522 (2009).

3. B. Li, X. Hu, H. Wang, International Journal of Advanced Manufacturing Technology. 30 (3-4). pp. 221-226 (2006). 
4. O. Smetannikov, K. Mogilnikov, Scientific and Technical Volga region Bulletin. 5. pp. 54-58. (2013).

5. V.Y. Duganov, O.B. Beshevli, T.A. Duyun Patent RU No. 169070 (2017)

6. O.B. Beshevli, T.A. Duyun, Bulletin of BSTU n.a. V.G. Shukhov. 4. pp. 102-108. (2018).

7. O.B. Beshevli, D.A. Bushuev, T.A. Duyun, V.G. Rubanov, Bulletin of BSTU named after V.G. Shukhov. 8. pp. 149-156. (2017). 